\title{
Investigação da aprendizagem de conceitos de óptica utilizando ilusões para turmas de pré-vestibular
}

Mara Fernanda Parisoto mara.parisoto@ufpr.br 0000-0001-6592-4915 Paraná, Brasil

Thais Rafaela Hilger hilger@ufpr.br

0000-0003-3463-3212 Universidade Federal do Paraná, Curitiba Paraná, Brasil

\begin{abstract}
RESUMO
Com o intuito de promover a aprendizagem, elaborou-se uma série de sugestões para ensinar óptica, a partir das ilusões, em um curso pré-vestibular popular de Porto Alegre. Esta proposta, desenvolvida a partir da Teoria da Aprendizagem Significativa de Ausubel, envolve atividades experimentais, lúdicas e simulações computacionais. Buscaram-se indícios de aprendizagem significativa nos conceitos de Física, especialmente no grupo onde se fez uso desta proposta, denominado grupo experimental, em contraposição ao grupo de controle, onde foram utilizadas aulas expositivas. Foi utilizado pré-teste e pós-teste e, a partir de tais dados, foi realizada análise estatística. Observou-se que ambos os grupos apresentaram indícios de Aprendizagem Significativa no pós-teste, entretanto o grupo experimental apresentou resultados significativamente melhores. Por ser o estudo das ilusões de óptica um conteúdo multidisciplinar, acredita-se que esta proposta pode ser utilizada em outras disciplinas.
\end{abstract}

PALAVRAS-CHAVE: Aprendizagem Significativa. llusões de óptica. Atividades experimentais. Pré-vestibular popular. 


\section{INTRODUÇÃO}

O ensino de Física e das demais ciências, é muitas vezes apresentado como algo estático, muito distante do cotidiano dos alunos. Talvez por este motivo o desinteresse por essa disciplina tem crescido entre os estudantes. Em contrapartida a essa realidade, foram elaboradas algumas propostas, como é o caso dos Parâmetros Curriculares Nacionais (BRASIL, 1996) e das diretrizes curriculares dos estados da região sul do Brasil (PARANÁ, 2009; RIO GRANDE DO SUL, 2009; SANTA CATARINA, 1998).

Partindo da premissa de que as atividades lúdicas e experimentais contribuem para uma aprendizagem mais efetiva de conteúdos, foi desenvolvida uma proposta para ensinar conceitos a partir da investigação de ilusões. Procurou-se relacionar as ilusões com conceitos de Física, demonstrando que, por trás da aparente "mágica", há fundamentos que podem contribuir para o estabelecimento de relações entre o mundo do aluno e o mundo das ciências.

Para preparar esta proposta, foi necessário: 1ํ) compreender quais são os processos envolvidos na construção das ilusões e a Física envolvida nessas questões; $2^{\circ}$ ) delimitar a área de conhecimento a fim de se explicar fenômenos complexos; 3ㅇ) relacionar as ilusões com outras áreas do conhecimento; 4ㅇ) entender como o sujeito se relaciona com o novo conhecimento a ser aprendido, de acordo com o referencial de aprendizagem adotado; 5ㅇ) analisar a abordagem a ser utilizada nas aulas, de modo que o aluno pudesse compreender os conceitos físicos relacionados às atividades propostas; 6ㅇ) propor atividades de ensino de Física que partissem das ilusões de Óptica, utilizando a Teoria de Aprendizagem Significativa (AUSUBEL, 2002), desenvolvendo, assim, habilidades para produzir materiais didáticos adequados para as aulas.

Foi confeccionada uma proposta de ensino contendo atividades experimentais, computacionais e demonstrativas, jogos, problematizações e explicações que relacionam as ilusões à Física. Ao se optar por atividades lúdicas como elemento motivador, houve a preocupação de criar um espaço interativo e criativo que favoreça a aprendizagem e possibilite a discussão acerca de novas possibilidades para ensinar Física. Buscaram-se indícios sobre a relação dessa proposta com a compreensão de conceitos físicos.

\section{JUSTIFICATIVA}

Em muitas escolas, o ensino ocorre através da reprodução de conteúdos que, na maioria das vezes, não motivam o interesse dos alunos. No caso da Física não é diferente. Soma-se a isto a dificuldade inerente a esta ciência, devido à sua própria linguagem e à distância entre a forma que o conteúdo frequentemente é abordado e a realidade do aluno. Para a maioria dos estudantes, esta falta de atrativos passa a impressão de que para saber Física é preciso decorar fórmulas e métodos de resolução de exercícios, que apenas servem para as provas. Além disso, a Física é ensinada como uma área do conhecimento isolada das demais, o livro texto ganha ênfase e as aulas são apenas teóricas, com exercícios repetitivos, que nada acrescentam ao raciocínio lógico. O interesse e o aprendizado acabam sendo postos de lado. 
Propostas como os Parâmetros Curriculares Nacionais (BRASIL, 1996) foram elaboradas na tentativa de minimizar esses problemas no ensino:

(...) num mundo como o atual, de tão rápidas transformações e de tão difíceis contradições, estar formando para a vida significa mais do que reproduzir dados, dominar classificações ou identificar símbolos, significa:

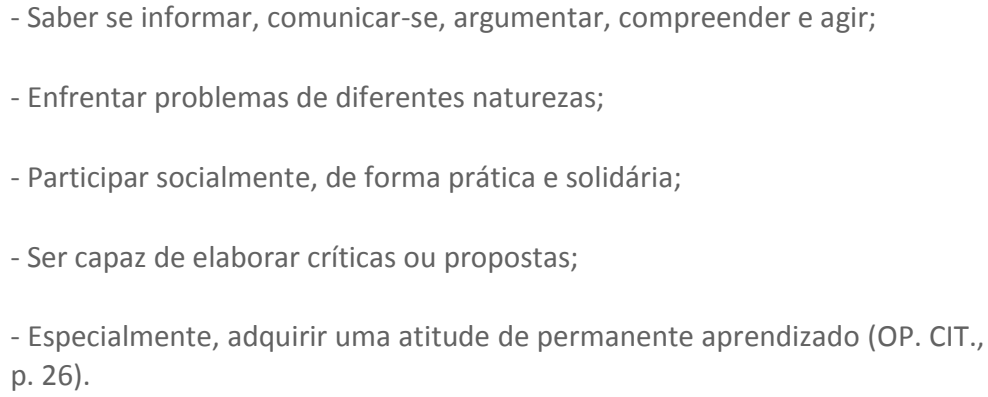

Assim, se faz necessário ensinar Física para a vida, para a cidadania, ou seja, preparar os alunos para lidar com situações reais (crises de energia, utilização de aparelhos eletrônicos e médicos, por exemplo).

No mesmo sentido, as Diretrizes Curriculares de Física do Paraná (2009), as Lições do Rio Grande (2009) e a Proposta Curricular de Santa Catarina (1998) sugerem que o conhecimento, incluindo o estudo da Física, deve expressar a importância das ciências e da percepção humana das regularidades naturais, de modo a dar sentido e importância ao que o aluno está aprendendo, mostrando que o ser humano, bem como a ciência, é instrumento e ao mesmo tempo resultado da sua capacidade de transformar o meio natural e a si mesmo.

\footnotetext{
Por isso, as ciências não são independentes das técnicas, das quais dependem e para as quais contribuem com o caráter histórico, expressado nas diferentes áreas científicas, revelam o trabalho de mediação entre homem e natureza, resultando nos conhecimentos que constituem nossa cultura (SANTA CATARINA, 1998, p. 34).
}

Muitos professores estão tentando se adequar a estas novas propostas, pois percebem que o papel da escola vai muito além de passar informações e que as ciências são importantes para o desenvolvimento da cidadania.

É do consenso dos professores de Física que a experimentação é necessária para a aprendizagem e que a junção da teoria com a prática contribui para o desenvolvimento do raciocínio lógico, para a argumentação e para o aumento da autonomia, ajudando o aluno a posicionar-se criticamente em relação a temas de ciência e tecnologia (dentre outros). Nesse sentido, as aulas experimentais podem deixar de ser simples demonstrações por parte dos professores ou apenas um espaço no qual os alunos manuseiam os instrumentos, sem relacionar a experimentação aos conceitos, tornando-se um ambiente agradável para discussão e aprendizagem. A criação e confecção de experimentos com materiais de baixo custo (e/ou sucatas) são uma alternativa para o professor que não possui recursos para obter materiais sofisticados. A utilização de tal abordagem permite ainda a facilidade na reposição de materiais, além de possibilitar que todos os alunos participem da atividade prática. 
Outro problema é a mera repetição e reprodução de conceitos, leis e princípios, sem que ocorra reflexão sobre suas relações, ou seja, sem a compreensão do contexto onde eles surgem. Esta deficiência é mais comum entre os estudantes, porém, pode ocorrer também entre professores, o que a torna ainda mais grave.

É necessário compreender a teia de relações em que cada conceito está envolvido para que o conteúdo possa fazer sentido para o aluno. De acordo com ROBILOTA \& BABICHAAK, 1997, p. 42):

[...] as teorias Físicas são as estruturas que representam este conjunto de conceitos, leis, princípios e convenções, unindo as leis e os fatos em uma unidade coerente, que na maioria das vezes é traduzida por um modelo. Cada conceito tem um significado e um lugar dentro da teoria, determinando a teoria ao mesmo tempo em que é determinado por ela. Os conceitos são articulados entre si de tal modo que partindo-se de um deles podemos chegar aos demais.

Quando o estudante não tem oportunidade de estar em contato com equipamentos elementares da tecnologia, a escola precisa oferecer essa aproximação, dando a ele não só acesso e condição de compreensão ativa dos principais meios de uso difundidos, mas encaminhando-o para uma participação efetiva, compreendendo além do domínio das técnicas, percebendo a importância do conhecimento e desenvolvendo o gosto pela ciência.

No Ensino Médio, principalmente devido à drástica redução da carga horária que vem ocorrendo nos últimos anos, dificilmente são abordados conteúdos de óptica e, se o são, a ênfase é dada a óptica geométrica. Conteúdos como dinâmica e cinemática com frequência são mais trabalhados ao longo do Ensino Médio. Além disso, em média, um quinto da prova do vestibular da Universidade Federal do Rio Grande do Sul (UFRGS), por exemplo, é composto por questões de óptica. Outro fator que influenciou a escolha de tal campo da Física foi à baixa existência de periculosidade, em relação a outras áreas, tais como a calorimetria, eletricidade, magnetismo e eletromagnetismo, na realização dos experimentos relacionados à óptica. Tal fator foi considerado uma vez que, turmas de pré-vestibular são muito numerosas e contam com apenas um professor, normalmente não apresentando espaço para laboratórios de Física. Um último fator que levou a esta escolha foi que a óptica fornece a possibilidade de desenvolver materiais de baixo custo, o que é dificilmente obtido no ensino da Física Moderna e Contemporânea.

As pesquisas de Moraes e Moraes (2000) e Araújo e Abib (2003) demonstram a importância de atividades experimentais no Ensino Médio e Superior. Entretanto, não há artigos na área que tratem da importância das atividades experimentais em pré-vestibulares. Nesta perspectiva, tem-se como objetivo pesquisar se atividades experimentais facilitam a aprendizagem de óptica em prévestibulares.

\section{REFERENCIAS TEÓRICOS}

Para entender as ilusões é preciso, em primeiro lugar, estabelecer quais os critérios envolvidos na percepção deste fenômeno e também definir qual teoria de 
compreensão. Os referencias adotados para tratar destes aspectos são apresentados a seguir.

Para compreender as ilusões é necessário entender sobre luz e as suas interações com a matéria, sobre o mecanismo das cores e sobre o olho humano, que é o órgão da percepção visual. A percepção visual é um campo de estudo que possui teorias já bem desenvolvidas, dividindo-se em: teoria da percepção direta ou ecológica e teoria da percepção indireta ou cognitivista.

Nas teorias diretas ou ecológicas, entende-se que a percepção é a captação de informações do ambiente, ou seja, a realidade está no meio e sua captação independe do observador. Já nas teorias indiretas ou cognitivistas, entende-se que as percepções são construídas a partir da seleção de estímulos e sensações que emergem da memória do indivíduo, ou seja, as imagens não são captadas diretamente do meio ambiente, mas são o produto de hipóteses, expectativas, fatores emocionais e estímulos externos. A principal diferença entre as teorias ecológicas e as teorias cognitivistas reside no fato de que, na primeira, apenas os estímulos externos são importantes, e na segunda, as experiências anteriores são fundamentais para o processo de visão. Dessa forma, duas concepções opostas concorrem: na primeira a realidade é independente do observador e na segunda a realidade só existe porque o observador existe.

Nesta pesquisa utiliza-se a teoria cognitivista, onde os conhecimentos anteriores são fundamentais para nossa percepção.

A abordagem cognitivista pode ser representada por Maturana (2001). Segundo este autor, na vida cotidiana e social, em nossa experiência humana, não se pode distinguir entre ilusão e percepção. Assim, não há uma única interpretação da realidade, cada ser observa o mundo de uma forma diferente, baseada em suas experiências anteriores. Este referencial está implícito nas atividades aqui desenvolvidas, a partir das ilusões de óptica.

Assim, o fenômeno da ilusão tem explicações baseadas nas teorias da percepção. A ilusão visual, conforme Gibson (1986), decorre da interpretação da informação que chega do ambiente até os nossos olhos e o que o cérebro interpreta ou produz. Ela inicia nos olhos e termina no córtex visual, dependendo tanto do ambiente externo como do interno.

A ilusão é uma percepção que não coincide com aquilo que ocorre no mundo material. Há diversos tipos de ilusões: de perspectiva, de contraste (PARISOTO \& HILGER, 2011), de luminosidade, de geometria, de movimento, de cor, de tamanho, etc. Pode-se dizer que elas surgem de ilusões reais dos sentidos e de interpretações habituais de um objeto. Muitas vezes, o registro óptico é correto e as ilusões existem apenas no cérebro. Podemos, então, classificar as ilusões em três tipos: óptica, sensorial e cognitiva (GIBSON, 1986).

As ilusões que ocorrem devido às características da luz são denominadas ilusões de óptica e ocorrem quando, por exemplo, se coloca uma moeda dentro de um copo (Figura 1a) e, ao adicionar água, é possível vê-la (Figura 1b). Este fenômeno ocorre devido apenas às propriedades da luz. 
Figura 1- Refração em copo de água.

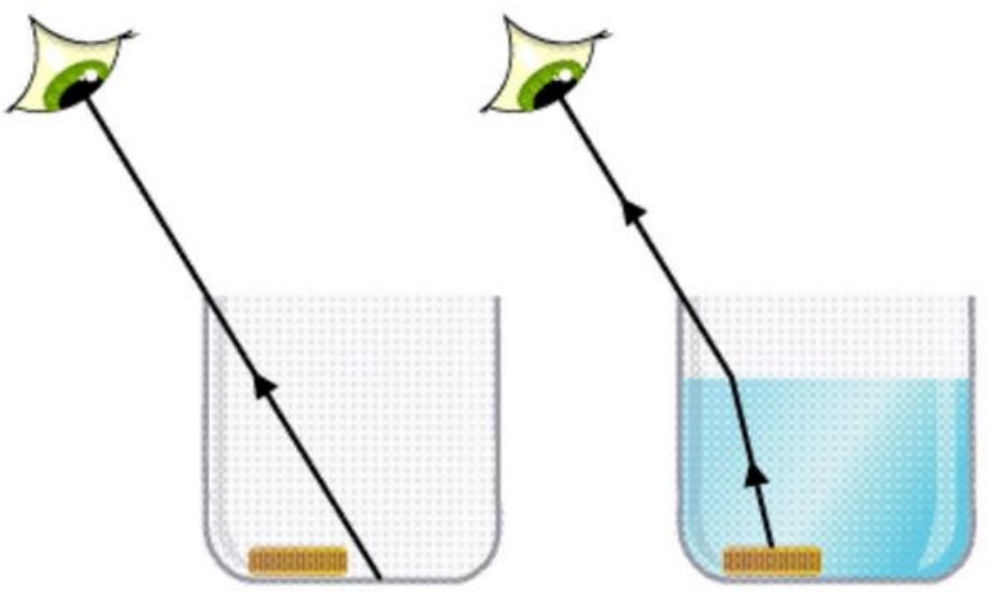

Fonte: http://www.sobiologia.com.br/conteudos/oitava_serie/optica8.php. Acesso: 17 de outubro de 2010

As ilusões sensoriais ocorrem quando alguma parte do aparelho visual nos engana, como é o caso das ilusões resultantes da sobreposição das cores e de imagens, como apresentado na Figura 2.

Figura 2- Exemplo ilusão sensorial.

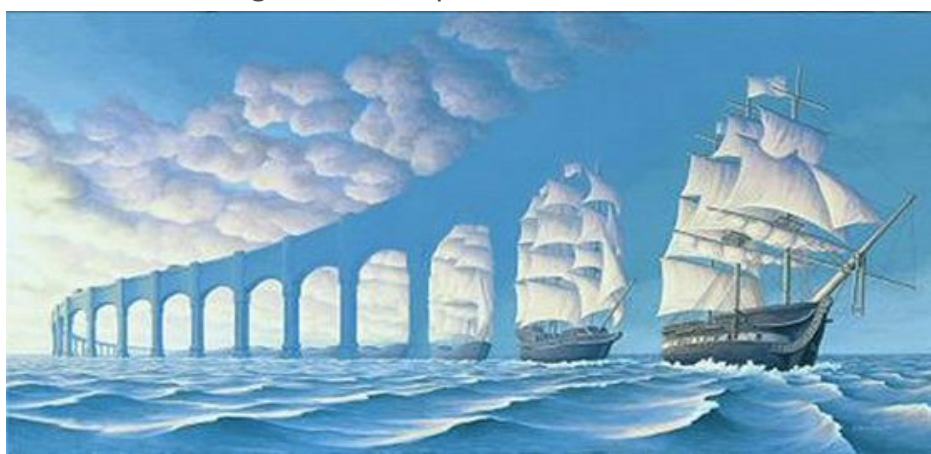

Fonte: www.webix.com.br. Acesso: 17 de outubro de 2010

Já as ilusões cognitivas têm origem no interior do cérebro, como, por exemplo, o caso do tamanho aparente da lua. Neste caso, segundo Silveira (2006), nosso aparelho receptor detecta que o tamanho da lua é o mesmo em todas as direções e, mesmo assim, temos a impressão de que a lua é maior quando nasce ou se põe, do que quando está sobre nossa cabeça.

Segundo Ausubel (2002), quem quer facilitar a aprendizagem significativa (AS) precisa identificar o conhecimento prévio do aluno e ensinar de acordo, pois esta é a variável isolada que mais influencia na AS.

A AS envolve a interação seletiva entre o novo material de aprendizagem e as ideias pré-existentes na estrutura cognitiva. Iremos empregar o termo ancoragem para sugerir uma ligação com as ideias pré-existentes ao longo do tempo. Por exemplo, no processo de subsunção, as ideias subordinadas pré-existentes fornecem ancoragem à AS de novas informações (OP. CIT., p. 3).

Para que a AS ocorra, é necessário que o novo conteúdo se relacione interativamente com a estrutura cognitiva do sujeito que está aprendendo, ou 
seja, que haja a interação do conhecimento novo e do antigo. O resultado deste processo, Ausubel chama de assimilação.

A AS é progressiva, ou seja, os significados são captados e internalizados progressivamente e, nesse processo, a interação social e a linguagem são decisivos.

No processo de AS, um elemento muito importante é a ancoragem cognitiva: ao adquirir novos conhecimentos de maneira significativa o sujeito ancora internamente as informações novas em seus subsunçores. Outro fator relevante para que ocorra a AS é que o aluno precisa estar predisposto a aprender.

Segundo Ausubel (op. cit.) o processo de detalhamento, refinamento e especificidade de um subsunçor é denominado princípio da diferenciação progressiva: neste, parte-se do geral (mais importante) rumo ao específico. Já a exploração das ligações entre conhecimentos, recombinando-os e relacionandoos, buscando as diferenças e semelhanças entre eles é conhecido por reconciliação integradora.

Esta teoria guiou a escolha das atividades e a abordagem dada ao conteúdo, visando uma possível melhora no desempenho dos estudantes no vestibular pelo aumento da disponibilidade de seus subsunçores.

\section{METODOLOGIA}

A pesquisa foi aplicada em duas turmas de pré-vestibular popular do Rio Grande do Sul: em uma delas foram elaborados alguns conteúdos de óptica através de atividades lúdicas (grupo experimental) e na outra os mesmos conteúdos foram abordados utilizando apenas aulas expositivas (grupo de controle). A turma experimental era composta por 64 alunos e o grupo de controle apresentava apenas oito estudantes.

Para o grupo experimental, foram realizados quatro encontros formais, de uma hora e meia cada, e uma oficina de quatro horas, totalizando dez horas de curso. Os encontros formais ocorreram no horário normal de aula, contando com a participação de 64 estudantes, no entanto, a oficina foi realizada extraclasse e, por ser opcional, apenas 26 alunos compareceram. O mesmo conteúdo foi apresentado no grupo de controle, em quatro aulas de uma hora e quarenta, totalizando seis horas e quarenta minutos de curso. Por ser em cursos populares, o público, em sua maioria, é formado por alunos de classe baixa que estudaram apenas em escolas públicas.

Apesar de o professor nas duas turmas não ser o mesmo, todo o conteúdo ministrado foi previamente combinado. Foi aplicado um teste antes da implementação do curso e reaplicado no final, sendo o mesmo nas duas turmas. Foi utilizado, apenas na turma experimental, um diário de bordo, onde foram registradas as informações consideradas relevantes. 
se os estudantes apresentavam aprendizagem equivalente nos dois casos. Deste modo, seria possível estabelecer um panorama sobre a influência das atividades propostas, para o ensino de óptica, no nível pré-vestibular.

\section{COLETA DE DADOS}

Antes da apresentação do conteúdo, os alunos foram instruídos a responderem um pré-teste (Apêndice 1) contendo 65 questões sobre óptica. Após a intervenção didática (utilizando as atividades propostas no grupo experimental e apenas aulas expositivas no grupo controle), solicitou-se que os estudantes respondessem o pós-teste, a fim de se avaliar quantitativamente sua evolução individual e, ainda, eventuais diferenças estatísticas significativas entre os dois grupos.

O pré-teste e pós-teste são compostos pelas mesmas 65 questões e foram validados e fidedignos. A validação ocorreu pela análise de conteúdo, sendo aprovado por três professores da UFRGS. Para o cálculo da fidedignidade, aplicouse o teste a 360 estudantes do Ensino Médio. 0 grupo e número foram escolhidos, pois, segundo Silveira (2010), para testar a fidedignidade do instrumento esse deve ser aplicado para grupos semelhantes ao que será pesquisado e para, pelo menos cinco vezes o número de questões que o questionário possui. A partir das respostas desses encontrou-se um coeficiente de Cronbach de 0,903, o qual, segundo Dancey e Reidy (2007) representa que o instrumento possui boa fidedignidade. A fidedignidade de um instrumento refere-se à estabilidade, à reprodutibilidade, à precisão das medidas com ele obtidas, ao grau de consistência dos valores medidos. Dessa forma um instrumento de coleta de dados perfeitamente fidedigno é aquele que se administrado duas vezes nas mesmas circunstâncias forneceria os mesmos dados (MOREIRA e ROSA, 2013).

A escolha e construção dos testes seguem os moldes dos vestibulares da região, uma vez que o objetivo final do curso é ser ingresso no Ensino Superior. Alguns estudantes já tiveram contato com o conteúdo no Ensino Médio e, neste momento, buscam relembrar, aprender e se preparar para a forma como as questões de óptica são abordadas no vestibular. Deste modo, questões abertas ou mesmo uma avaliação continuada não corresponderiam às expectativas dos alunos ou à proposta do curso.

\section{ANÁLISE DOS DADOS}

A análise dos dados foi realizada através de diagnóstico quantitativo do préteste e do pós-teste, tanto para o grupo experimental quanto para o de controle. Realizou-se o teste T para variáveis independentes (ibid.), a comparação de médias dos acertos (incluindo a variância e o desvio padrão dos mesmos) e análise sobre o ganho para cada grupo e entre os grupos (SILVEIRA, 2010). Todos os procedimentos foram realizados com o auxílio do pacote estatístico SPSS 8.0.

Para tratar sobre o ganho, seguiram-se os passos propostos por Silveira (ibid):

1ํ) Calcular a diferença entre o número de acertos no pré-teste e no pós-teste

2ํ) Calcular a média de acertos a mais no pós-teste; 
3ํ) Calcular o desvio padrão (SG);

4ㅇ) Verificar o nível de significância destes valores (t);

5) Comparar os resultados com o valor teórico previsto, verificando a probabilidade de a diferença encontrada ser devida a fatores externos.

Para auxiliar na compreensão desses dados, analisou-se ainda o diário de bordo, onde foram anotados os conteúdos e questionamentos contemplados em aula, e também alguns pontos que chamaram atenção. Além da análise dos resultados, o próprio curso foi avaliado, com o intuito de realizar eventuais mudanças.

\section{DESCRIÇÃO DO DIÁRIO DE BORDO}

Foi feito o diário de bordo apenas no grupo experimental, uma vez que no grupo controle se adotou a sequência e grau de aprofundamento dos conteúdos conforme a apostila do curso pré-vestibular. Portanto, serão discutidas, nesta seção, apenas questões relativas ao grupo experimental.

Em um curso pré-vestibular é mais apropriado utilizar-se demonstrações de experimentos, principalmente devido ao pouco tempo de que se dispõe. Optouse, então, por uma metodologia que intercalasse aulas expositivas dialogadas, aulas demonstrativas com atividades experimentais, resolução de exercícios de vestibular, tanto pelos alunos - em grupos ou individualmente - quanto pelo professor e correções explicativas desses exercícios no quadro. Na oficina foi oportunizada a manipulação das atividades experimentais pelos próprios alunos, aproveitando a maior disponibilidade de tempo, favorecendo os diferentes tipos de aprendizagem: auditiva, cinestésica e visual, assim como sugerem Prain e Waldrip (2006) e Moreira (2005).

Em todas as aulas buscou-se partir do que o aluno sabia, tendo em vista a proposição de que o professor precisa partir dos conhecimentos pré-existentes na estrutura cognitiva dos alunos (conhecimentos prévios) para ensinar. Este também foi o objetivo do pré-teste, que auxiliou na identificação dos conhecimentos que os alunos apresentavam antes das aulas. Se os estudantes mostravam conhecimento sobre algum assunto, este era utilizado para ensinar conceitos relacionados. Por outro lado, se desconheciam determinado tema, este era mais enfatizado nas explicações. A avaliação formal do desempenho dos alunos não é realizada em cursos pré-vestibulares e o diário de bordo tem por objetivo auxiliar no entendimento da proposta de ensino. Feitas estas considerações, a seguir é apresentado o resumo do diário de bordo para cada um dos seis encontros. 
O Inicialmente, solicitou-se aos alunos que respondessem o pré-teste (Apêndice 1), para identificar seus conhecimentos prévios e ensinar de acordo (AUSUBEL, 2002) e também para comparar com os resultados do pós-teste e com os resultados do grupo de controle, buscando indícios sobre o atendimento ou não dos objetivos da proposta. Após, foram abordadas as características das ondas longitudinais, transversais e eletromagnéticas, com o auxílio de uma corda e de uma mola. A partir desses conceitos - comprimento de onda, frequência, amplitude, energia, etc. - tratou-se sobre o efeito Doppler e suas aplicações, como por exemplo, em ultra-sonografias e no trânsito, utilizando, para demonstrar esse efeito, a atividade 1 (Apêndice 2). A seguir, foi utilizada a atividade 2 (Apêndice 2) para tratar dos fenômenos de interferência e explorar as relações entre os conceitos vistos até aqui e a visão de diferentes cores.

Em seguida, utilizou-se a atividade 3 (Apêndice 2), para explicar a persistência retiniana, que apresenta diferentes aplicações, como, por exemplo, na confecção dos desenhos animados. A partir da persistência retiniana também se pode explicar o funcionamento do disco de Newton e do efeito estroboscópio, discutidos com a utilização, respectivamente, das atividades 4 e 5 (Apêndice 2).

Foi entregue aos estudantes uma lista de exercícios de vestibular da UFRGS, pois todos prestariam prova para esta Universidade. Solicitou-se que fossem respondidas as questões relativas ao assunto da aula, que, em seguida, foram corrigidas no quadro.

Após, foi realizada uma problematização sobre as características dos espelhos planos, solicitando que os alunos escrevessem no papel suas ideias sobre o que se estava questionando. Na sequência foi apresentada a atividade 6 (Apêndice 2) e solicitou-se que as características dos espelhos planos fossem identificadas e comparadas às predições escritas em papel.

Utilizando a atividade 7 (Apêndice 2) perguntou-se aos alunos o que eles achavam que iria ocorrer se o ângulo entre os espelhos planos fosse modificado. A seguir foi preenchida uma tabela no quadro com diferentes ângulos formados entre os espelhos e a quantidade de imagens que eram vistas. A partir dessas anotações deduziu-se no quadro uma equação para o número de imagens em função do ângulo. Foi apresentada a atividade 8 (Apêndice 2) como aplicação desta equação.

Outros exercícios de vestibular, que se encontravam na lista previamente entregue pelo professor, foram resolvidos pelos alunos e corrigidos no quadro. $\mathrm{O}$ gabarito completo da lista foi entregue ao final da aula, para que os estudantes pudessem estudar em casa. 


\section{SEGUNDO ENCONTRO}

Relembraram-se rapidamente os assuntos da aula anterior e um exercício sobre associação de espelhos planos foi respondido oralmente pela classe.

Neste encontro utilizou-se o método Predizer, Observar e Interagir (TAO \& GUNSTONE, 1999). A atividade 9 (Apêndice 2) foi apresentada e os alunos deveriam escrever sua explicação para o que foi observado. Abordou-se o conteúdo de refração a partir da Lei de Snell, associado ao uso de exemplos. Posteriormente, os alunos foram instigados a resolverem e corrigirem exercícios de vestibular. Voltou-se, então, à questão envolvida na atividade 9 (Apêndice 2) e os estudantes analisaram o que haviam escrito anteriormente, modificando suas suposições a partir dos conteúdos ensinados e da observação do ocorrido na atividade experimental.

Utilizou-se a atividade 10 (Apêndice 2) para realizar medições quanto aos ângulos de incidência, reflexão e refração de acordo com a quantidade de espelhos. Aproveitou-se a oportunidade para tratar sobre os prismas e suas características. A seguir, os alunos resolveram dois exercícios de vestibular referente à refração, que foram corrigidos no quadro em conjunto com a turma.

A reflexão interna total foi tratada conceitualmente a partir das atividades 11 e 12 (Apêndice 2) e, em seguida, formalizada com o auxílio da Lei de Snell. Solicitou-se que na aula seguinte os estudantes trouxessem uma colher ou uma concha de cozinha bem polida.

\section{TERCEIRO ENCONTRO}

Novamente a aula foi iniciada com uma revisão das aulas anteriores. A seguir, tratou-se de espelhos esféricos (côncavos e convexos) e sobre o comportamento geométrico da trajetória dos raios de luz, para determinar onde se forma a imagem nesses espelhos. Algumas situações foram apresentadas para que os alunos determinassem onde a imagem seria formada. Em seguida, foi solicitado que comparassem esta predição ao que observaram na superfície, externa e interna, da concha ou colher que trouxeram.

Preencheu-se um quadro comparativo entre lentes e espelhos, apontando suas diferenças e semelhanças. Utilizou-se esse conhecimento para auxiliar no entendimento nesta atividade. Além disso, estudou-se o comportamento de lentes convergentes utilizando a lâmpada construída na atividade 13 (Apêndice 2), mostrando-se que esse sistema aumenta o tamanho dos objetos e que, quando colocado sob uma fonte de luz, os raios convergem.

Solicitou-se aos alunos que resolvessem alguns exercícios de vestibular sobre lentes e espelhos esféricos para a aula seguinte.

\section{QUARTO ENCONTRO}

Retomaram-se as ideias sobre lentes a partir da correção dos exercícios solicitados.

Página | 72

O mecanismo da visão foi abordado, através de aula expositiva-dialogada, enfatizando como a imagem é formada em nossos olhos (fisiologia dos olhos, 
problemas da visão e lentes que auxiliam em sua correção) e transmitida para o cérebro, abordando o efeito fotoelétrico.

Uma tabela-resumo sobre óptica Física e Geométrica foi construída no quadro, em parceria com os alunos. Solicitou-se a eles que resolvessem alguns exercícios de vestibular e alguns foram corrigidos no quadro logo em seguida.

Os alunos foram convidados a participar da oficina extraclasse.

\section{OFICINA}

A oficina extraclasse foi realizada entre o quarto e o quinto encontro.

No início da oficina foi elaborado no quadro, em conjunto com os alunos, um mapa conceitual (MOREIRA, 2006), contemplando o conteúdo de óptica visto nas quatro aulas. Em seguida, a turma foi dividida em 13 duplas e a aula em duas etapas.

Na primeira etapa, cada dupla recebeu uma das 13 atividades do Apêndice 2 e uma lista de questões do vestibular da UFRGS. Os alunos estudaram a atividade recebida e resolveram alguns exercícios da lista relacionados com a atividade. $\mathrm{Na}$ segunda etapa, cada dupla apresentou e explicou o experimento recebido e, após, resolveu no quadro os exercícios escolhidos da lista. Sendo assim, o professor, além de utilizar os conhecimentos prévios dos alunos, pode identificar conhecimentos de senso comum e auxiliar na evolução dessas ideias, para que se tornem conhecimentos cientificamente aceitos.

Promoveu-se a discussão sobre os temas apresentados, a partir da demonstração feita pelas duplas, enquanto os problemas eram resolvidos no quadro. O professor teve papel mediador e encaminhador nessa discussão e auxiliou na adequada solução dos problemas, de acordo com a forma de resolução exigida pelo vestibular da UFRGS.

\section{QUINTO ENCONTRO}

No início da aula foi solicitado que os alunos respondessem o pós-teste (Apêndice 1). Em seguida, iniciou-se o próximo conteúdo da programação do prévestibular.

\section{RESULTADOS}

Na Tabela 1 são apresentados os resultados do pré-teste e do pós-teste, tanto para a turma de controle quanto para a experimental. Para o grupo de controle, 8 alunos estavam presentes na aplicação do pré-teste e 7 no pós-teste. Já para grupo experimental, dos 64 que participaram do curso, apenas 26 realizaram o pré-teste e 29 o pós-teste, sendo que o primeiro está contido no segundo. 
Tabela 1- Resultados das respostas ao pré-teste e pós-teste.

\begin{tabular}{|c|c|c|c|c|c|}
\hline Teste & Grupo & Respondentes & Questões & $\begin{array}{c}\text { Média de } \\
\text { acertos }\end{array}$ & $\begin{array}{c}\text { Desvio } \\
\text { padrão }\end{array}$ \\
\hline Pré-teste & Experimental & 26 & 65 & 19,54 & 10,43 \\
\hline Pré-teste & Controle & 7 & 65 & 17,4 & 4,322 \\
\hline Pós-teste & Experimental & 29 & 65 & 26,34 & 10,751 \\
\hline Pós-teste & Controle & 8 & 65 & 19,25 & 7,246 \\
\hline
\end{tabular}

Das 65 questões do pré-teste, os acertos oscilaram entre 0 e 36 para o grupo experimental e entre 0 e 24 para o grupo de controle. Para o pós-teste, os acertos oscilaram entre 6 e 45 para o grupo experimental e entre 11 e 32 para o grupo de controle. O desvio padrão, sobre a média de acertos em cada teste, no grupo controle é inferior ao valor obtido no grupo experimental.

Para testar a significância das médias obtidas, para todas as situações, foi utilizado o teste T para amostras independentes (DANCEY \& REIDY, 2007). Não foi possível rejeitar a hipótese nula, que afirma que não existe relação entre dois fenômenos medidos, pois a significância obtida de 0,376 está acima do valor teórico estipulado $(0,05)$ (Ibid.). Com base nestas informações pode-se afirmar que os grupos (controle e experimental) são diferentes e que o pré-teste não pode ser usado como indicador da homogeneidade inicial dos grupos. Portanto, foi realizada a análise de ambos em termos do ganho (SILVEIRA, 2010).

\section{RESULTADOS PARA O GRUPO EXPERIMENTAL}

A partir do número de acertos individuais do grupo experimental, calculou-se a diferença entre o número de acertos no pré-teste e no pós-teste, procedendo-se então ao cálculo do ganho médio, obtendo-se 15,8, ou seja, em média, 15,8 questões foram acertadas a mais no pós-teste do que no pré-teste, com desvio padrão de 2,14 questões. Os resultados obtidos para o grupo experimental são expressos na Tabela 2.

Tabela 2- Resultados para o grupo experimental.

\begin{tabular}{|c|c|c|}
\hline $\mathrm{n}_{\mathrm{e}}$ & número de sujeitos & 26 \\
\hline $\mathrm{G}_{\mathrm{e}}$ & ganho médio & 15,8 \\
\hline $\mathrm{SG}_{\mathrm{e}}$ & desvio padrão do ganho médio & 20,14 \\
\hline $\mathrm{t}_{\mathrm{e}}$ & Significância & 00,38 \\
\hline
\end{tabular}


Pela razão $t$ de Student (DANCEY \& REIDY, 2007) tem-se, para este caso, 25 graus de liberdade (já que 26 participantes responderam o pré-teste e o pós-teste e o grau de liberdade é calculado com o número de participantes menos 1) cujo nível de significância teórico é igual a 2,79 a 1\%. Para o grupo experimental, a significância obtida foi de 7,38. Isto indica que a probabilidade de a diferença média entre o pós-teste e o pré-teste ter ocorrido por acaso é menor do que $1 \%$. Assim, pode-se inferir que o aumento de acertos no pós-teste em relação ao préteste se deve a aquisição de novos conhecimentos pela turma experimental.

\section{RESULTADOS PARA O GRUPO CONTROLE}

A partir do número de acertos individuais do grupo de controle, calculou-se a diferença entre o número de acertos no pré-teste e no pós-teste, procedendo-se então ao cálculo do ganho médio (soma das diferenças dividido pelo número de sujeitos), obtendo-se 8,86 , ou seja, em média, 8,86 questões acertadas a mais no pós-teste do que no pré-teste, com desvio padrão de 3,21 questões. Os resultados obtidos para o grupo experimental são expressos na Tabela 3.

Tabela 3- Resultados para o grupo controle.

\begin{tabular}{|c|c|c|}
\hline $\mathrm{n}_{\mathrm{c}}$ & número de sujeitos & 7 \\
\hline $\mathrm{G}_{\mathrm{c}}$ & ganho médio & 8,86 \\
\hline $\mathrm{SG}_{\mathrm{c}}$ & desvio padrão do ganho médio & 3,21 \\
\hline $\mathrm{t}_{\mathrm{c}}$ & Significância & 2,79 \\
\hline
\end{tabular}

De acordo com a razão t de Student (Ibid.) tem-se, para o grupo controle, 6 graus de liberdade, cujo nível de significância teórico é igual a 2,45 a 5\%. A significância obtida para este grupo foi 2,76 que é, portanto, superior ao estabelecido. Ou seja, indica que a probabilidade da diferença média entre o pós e o pré-teste ter ocorrido por acaso é menor que $5 \%$. Assim, pode-se inferir que o aumento de acertos no pós-teste em relação ao pré-teste se deve a aquisição de novos conhecimentos pelos estudantes.

\section{GRUPO EXPERIMENTAL X GRUPO DE CONTROLE}

Calculou-se nas duas seções anteriores o desvio padrão, respectivamente, do grupo experimental e do grupo controle, para buscar indícios de AS pelos grupos. Nesta seção são apresentados dados para ambos os grupos, a fim de identificar qual grupo apresentou mais indicativos de AS.

A partir do número de respondentes do grupo experimental e controle e do desvio padrão de ambos, que constam respectivamente nas Tabelas 2 e 3, obtevese o desvio padrão, entre os grupos, de 1,89 pontos para mais ou para menos da média. 
Tabela 4- Comparação entre os grupos

\begin{tabular}{|c|c|c|}
\hline Grupo & Experimental $(\mathrm{e})$ & Controle $(\mathrm{c})$ \\
\hline $\begin{array}{c}\text { número de sujeitos que responderam o } \\
\text { pré-teste e o pós-teste }(\mathrm{n})\end{array}$ & 26 & 7 \\
\hline ganho médio (G) & 15,8 & 8,86 \\
\hline desvio padrão do ganho médio (SG) & 2,14 & 3,21 \\
\hline significância (t) & 7,38 & 2,79 \\
\hline
\end{tabular}

O nível de significância obtido foi 3,67 e, nesse nível, a probabilidade de que a diferença média entre o pós-teste e o pré-teste tenha ocorrido por acaso é menor do que $5 \%$. Ou seja, a probabilidade de que a diferença entre as respostas no préteste e do pós-teste seja devido ao aumento de conhecimentos dos alunos, ocasionado pela aplicação do curso, é maior do que $95 \%$.

Embora os dois grupos tenham melhorado significativamente seus conhecimentos sobre o tema abordado, no pós-teste em relação ao pré-teste, o grupo experimental aumentou os acertos, em média, quase quatro vezes mais que o grupo de controle $(10,46 \%$ de acréscimo no grupo experimental contra $2,86 \%$ de acréscimo no grupo controle).

Portanto, houve um aumento considerável de acertos no grupo experimental e uma diferença significativa entre os acertos ao se comparar ambos os grupos. Assim, a hipótese de que as atividades sugeridas auxiliam no aprendizado de óptica foi validada.

A partir da realização desta pesquisa, algumas medidas podem ser tomadas para melhoria das atividades e do rendimento dos estudantes, dentre elas destacaram-se:

1. A manipulação de todas as atividades experimentais pelos próprios alunos, deixando de lado a simples demonstração;

2. Em conjunto com as atividades experimentais e resolução de questões, realizar outras atividades, como: mapas conceituais e diagramas V (Moreira, 2006), utilização de simulações, vídeos, etc., que estimulam o estudante a pensar melhor nos conceitos abordados;

3. Realizar mais atendimentos extraclasse, com o ensino mais individualizado e maior atenção às dificuldades de cada aluno;

4. Estimular a formação de grupos de estudo, pois a resolução de exercícios é importante para a compreensão de conceitos e, no caso de cursos prévestibulares, esta é uma necessidade inerente;

5. Oferecer mais oficinas extraclasse, em que seja possível aproximar a teoria (equações, leis, conceitos) à prática (problemas, demonstrações, experimentos); 
6. Sugerir e estimular a realização de atividades experimentais, com materiais de baixo custo, em pequenos grupos, com posterior apresentação em classe, para os colegas, sempre utilizando conceitos físicos.

É importante ressaltar que, muitas das atitudes sugeridas não foram previamente tomadas devido ao público alvo pertencer a um curso pré-vestibular. Também decorre daí a excessiva preocupação com o número de exercícios de vestibular a serem discutidos e alguns empecilhos originados na forma de atuação dos cursos deste tipo. Por exemplo, a disponibilidade do professor para atividades extraclasse é difícil, principalmente em cursos de pré-vestibular popular, pois a atividade não é remunerada e normalmente o professor possui vínculo empregatício em outra instituição. No caso do curso popular, onde os professores são voluntários, torna-se ainda mais difícil encontrar candidatos a suprir essas lacunas. Outro problema é a escolha dos conteúdos pelos vestibulares, que também não leva em conta o que o professor considera relevante. Devido à quantidade de conteúdos solicitados no vestibular, por vezes se faz necessário abordar uma visão muito geral do conteúdo, sem dar-lhe o devido aprofundamento.

O ideal é que o professor tenha a liberdade de escolha em sua disciplina, mas quando esta não ocorre a contento pode-se inserir algumas atividades interessantes e que motivem os estudantes a estudar mais profundamente em casa.

\section{CONSIDERAÇÕES FINAIS}

Em muitas escolas brasileiras, o ensino de ciências utiliza metodologias baseadas na repetição: muitos educadores entendem a memorização como sinônimo de aprendizagem e, nesse sentido, o aluno aprende quando é capaz de reproduzir algo em uma prova, que da mesma forma que o ensino, é descontextualizada e muito distante da realidade do aluno. Sendo assim alunos que vão muito bem na escola, muitas vezes, não apresentam o mesmo rendimento em outros contextos, pois a memorização dificilmente torna-se significativa para o aluno.

Para facilitar a aprendizagem é preciso que aluno esteja interessado e, para tanto, é fundamental que o conteúdo desperte sua curiosidade. Nesse sentido, as ilusões podem contribuir para o ensino de Física. Diversos estudos (MEDEIROS \& MEDEIROS, 2005; HILGERT \& ARISI, 2003; FIGUEIREDO \& PIETROCOLA, 2002) apontam a ludicidade como fonte de motivação. Entre as atividades lúdicas têmse os jogos, as brincadeiras, as atividades experimentais, etc. Estas atividades permitem que sejam criadas e propostas novas atividades, com abordagens alternativas do conteúdo. Possibilitam ainda o melhor entendimento de conceitos e equações através de questionamentos não habituais.

Outros estudos utilizam atividades semelhantes às apresentadas (CAMPOS, FERNANDES \& RODRIGUES, 2011; CATELLI \& LIBARDI, 2011; IMBERNON ET AL., 2009; LUDKE, 2010; MEDEIROS, 2005; ORTIZ, LABURÚ \& SILVA, 2010; ROCHA, ET AL., 2010), porém, em geral, elas são realizadas em minicursos ou no ensino regular. Esta proposta foi implementada em um curso pré-vestibular popular, um 
atividades diferenciadas, como as aqui propostas, apresentam potencial motivador para o ensino de Física e de ciências, pois provocam a curiosidade dos alunos e se relacionam a sua realidade. Deste modo, pode ocorrer um ganho na aprendizagem do aluno que se prepara para o vestibular, pois, ao se sentir motivado, estuda mais em casa, relaciona melhor os conteúdos e compreende melhor os problemas.

Generalizando estes resultados, esta proposta pode ser realizada em turmas de qualquer natureza, desde que tenha o aprofundamento adequado do conteúdo, para turmas de educação formal (Ensino Fundamental, Médio, de Jovens e Adultos, etc.) ou informal (feiras de ciências, exposições, mostras, etc.). Também o estudo das cores, e outros aspectos interessantes ligados à Física, são potencialmente multidisciplinares e, portanto, podem ser utilizados em projetos que envolvam diferentes disciplinas. 


\title{
Optical concepts learning research using illusions for pre-vestibular classes
}

\begin{abstract}
With the intention of improve learning of optics concepts, we promoted a series of suggestions for teaching, from illusions, in a popular pre-college course of Porto Alegre. This proposal, developed from the Theory of Meaningful Learning of Ausubel, involves computer simulation, experimental and ludic activities. We sought evidence on improving in the understanding of physics concepts, especially in the group that used our proposal (experimental group). In the control group we mainly used lectures. We used pre-test and post-test and from the obtained data, we did a statistical analysis to evaluate the results. We observed that both groups showed signs of meaningful learning in the post-test, however, the experimental group had significantly better results. Because the study of optical illusions is multidisciplinary, we believe that this proposal can be develop in other subjects either.
\end{abstract}

KEYWORDS: Meaningful learning. Optics illusion. Experimental activities. Popular precollege. 


\section{NOTAS}

1 Área de Ensino de Ciências e Matemática, segundo a Coordenação de Aperfeiçoamento de Pessoal de Nível Superior (CAPES), classificados como qualis A1 nacionais e internacionais, no período de 2000 à 2012

2 Nesta pesquisa, optou-se por utilizar um questionário na identificação dos possíveis conhecimentos prévios.

\section{REFERÊNCIAS}

Araújo, M. S. T. de; Abib, M. L. V. dos S. (2003). Atividades experimentais no ensino de Física: diferentes enfoques, diferentes finalidades. Revista Brasileira de Ensino de Física, 25(2), 176-194.

Arribas, S. D. (1996). Experiência de física na escola. Passo Fundo: EDIUPF.

Ausubel, D. P. (2002). Retenção e aquisição de conhecimento: uma perspectiva cognitiva. Lisboa: Plátano.

Berlitz, Â. M. J. (1996). Experiências de Física para o 1o grau. São Paulo: UNISINOS.

Brasil. (1996). Parâmetros Curriculares Nacionais: ciências da natureza, Matemática e suas tecnologias. Brasília, Distrito Federal, p. 58.

Campos, E.; Fernandes, T. J.; Rodrigues, N. A. S. (2011). O princípio de Huygens, a óptica de Fourier e a propagação de feixes de laser. Revista Brasileira de Ensino de Física, 32(3), 1-9.

Catelli, F.; Libardi, H. (2011). CDs como lentes difrativas. Revista Brasileira de Ensino de Física. 32(2), 1-6.

Dancey, C. P.; Reidy, J. (2007). Estatística sem matemática para Psicologia: Usando SPSS para Windows. São Paulo: ARTMED.

Figueiredo, A.; Pietrocola, M. (2002). Física, um outro lado: luz e cores. São Paulo: FTD.

Gaspar, A. (2003). Física: ondas, óptica, termodinâmica. São Paulo: Ática. 
Hilgert, J.; Arisi, R. (2003). Os conteúdos na educação informal a partir da ludicidade. Monografia, Universidade Comunitária de Chapecó, Chapecó, Santa Catarina, Brasil.

Imbernon, R. A. L.; Toledo, M. C. M.; Honório, K. M.; Tufaile, A. P. B.; Vargas, R. R. S.; Campana, P. T.; Falconi, S.; Infante-Malachias, M. E. (2009). Experimentação e interatividade (hands-on) no ensino de ciências: a prática na práxis pedagógica. Experiências no Ensino de ciências, 4(1), 79-89.

Ludke, E. (2010). Um indutímetro para laboratório didático de eletromagnetismo. Revista Brasileira de Ensino de Física, 32(1), 1-4.

Maturana, H. (2001). Cognição, ciência e vida cotidiana. Belo Horizonte: Editora UFMG.

Medeiros, A. (2005). A História e a Física do fantasma de Pepper. Caderno Brasileiro do Ensino de Física, 23(3), 329-344.

Medeiros, A.; Medeiros, C. F. de. (2005). Einstein: a Física dos brinquedos e o princípio da equivalência. Caderno Brasileiro do Ensino de Física, 22(3), 299-315.

Moraes, A. M.; Moraes, I. J. (2000). A avaliação conceitual de força e movimento. Revista Brasileira de Ensino de Física, 22(2), 232-246.

Moreira, M. A. (2005). Aprendizagem Significativa Crítica. Porto Alegre: Instituto de Física da UFRGS.

Moreira, M. A. (2006). Mapas Conceituais e Diagramas V. Porto Alegre: Ed. do autor.

Moreira, M. A.; Rosa, P. R. da S. (2013). Uma Introdução à Pesquisa Quantitativa em Ensino. Campo Grande: Editora UFMS.

Ortiz, A. J.; Laburú, C. E.; Silva, O. H. M. da. (2010). Proposta simples para o experimento de espalhamento de Rayleigh. Caderno Brasileiro do Ensino de Física, 27(3), 599-608.

Paraná. (2009). Diretrizes Curriculares de Física. Curitiba, Paraná, p.126. 12(2), 48-52. 
Prain, V.; Waldrip, B. (2006). An exploratory study of teachers' and students' use of multi-modal representations of concepts in primary science. International Journal of Science Education, 28(15), 1843-1866.

Ribas, S. D. (1996). Experiência de física na escola. Passo Fundo: EDIUPF.

Rio Grande do Sul. (2009). Lições do Rio Grande. Porto Alegre, Rio Grande do Sul, p.124.

Robilota, M. B.; Babichaak, C. C. (1997). Definições e conceitos em Física. Cadernos Cedes, 41(1), 35-45.

Rocha, M. N.; Fugimotto, T. G.; Azevedo, R. S.; Muramatsu, M. (2010). O azul do céu e o vermelho do pôr do Sol. Revista Brasileira de Ensino de Física, São Paulo, 32(3), 3501-3505.

Santa Catarina. (1998). Proposta Curricular de Santa Catarina. Florianópolis, Santa Catarina, p.148.

Silveira, F. L. da. (2006). A visão sobre o tamanho da Lua no horizonte. A Física na Escola, 7(2), 67-69.

Silveira, F. L. da. (2010). Determinando a significância estatística para as diferenças entre as médias. Texto de apoio, Recuperado em 17 de outubro, 2010, de: http://www.if.ufrgs.br/ lang/Textos/Comparacoes_em_media.pdf

Tao, P. K.; Gunstone, R. F. (1999). The process of conceptual change in force and motion during computer-supported physics instruction. Journal of Research in Science Teaching, 36(7), 859-882.

Valadares, E. de C. (2000). Física mais que divertida. Belo Horizonte: UFMG.

\section{APÊNDICE 1: PRÉ-TESTE E PÓS-TESTE.}

Este teste visa obter informações sobre o seu conhecimento referente a alguns conceitos de óptica. Siga as instruções abaixo para o bom encaminhamento do teste.

1.Procure não "chutar" - sempre existe uma opção que diz "não sei". Esta é a opção que deve ser marcada, caso você não consiga identificar a resposta que mais se aproxime de suas concepções, porém sempre que possível utilize as outras opções. 
2.Você não deve se identificar. O teste vem numerado para que possamos distinguir os resultados, possibilitando a segurança de sua identidade. Em virtude de o teste ser numerado, procure não rasurar o mesmo, pois isto dificultará o trabalho de análise.

Assinale apenas uma alternativa para cada questão, observando a seguinte escala:

C= Concordo; NS = Não sei; $D$ = Discordo

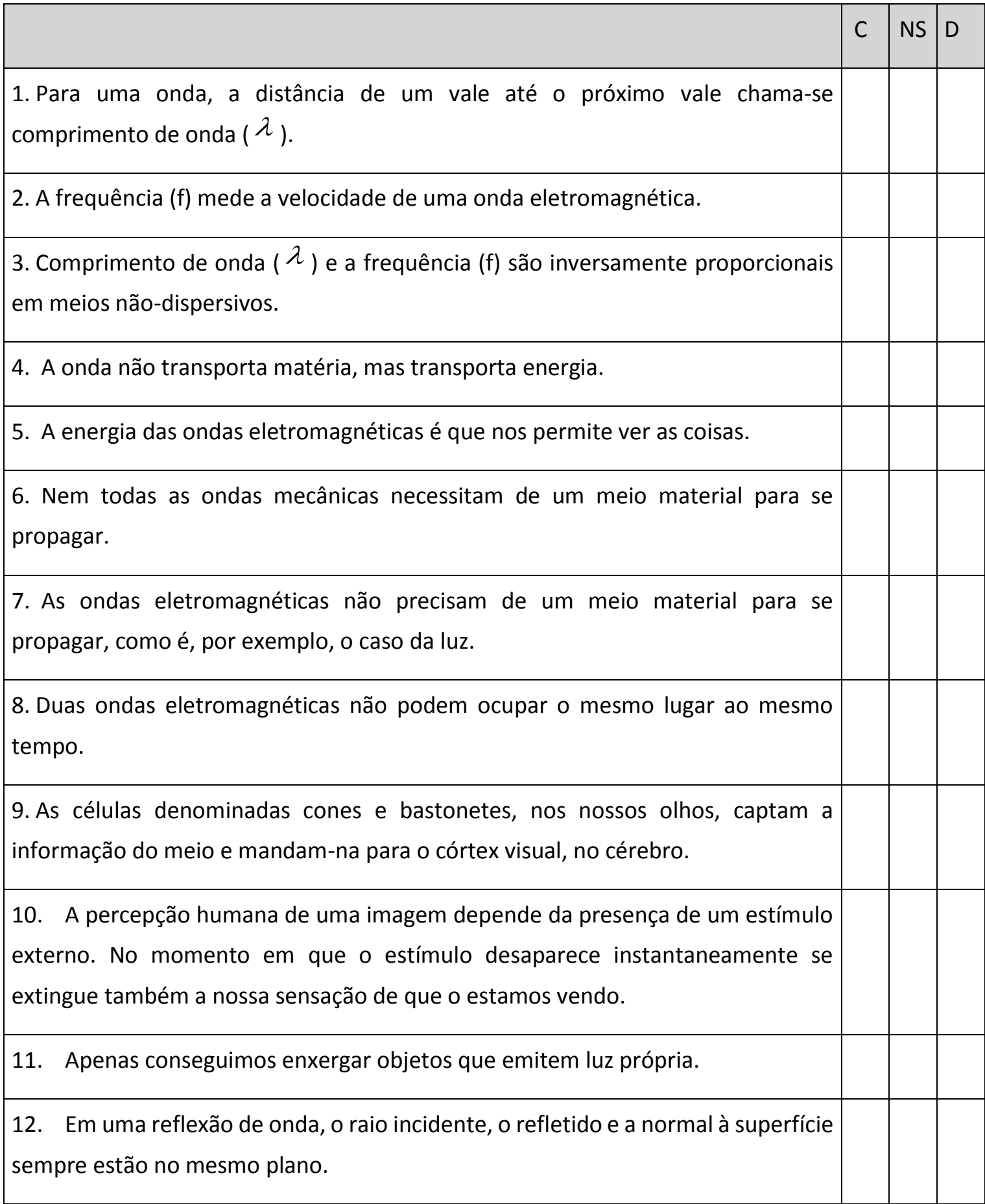




\begin{tabular}{|c|c|c|c|}
\hline & C & NS & D \\
\hline $\begin{array}{l}\text { 13. Em uma reflexão regular de uma onda, o raio incidente sempre faz um ângulo } \\
\text { reto com o raio refletido. }\end{array}$ & & & \\
\hline 14. Um espelho plano conjuga, para um objeto real, uma imagem virtual. & & & \\
\hline 15. Um espelho plano conjuga, para um objeto real, uma imagem inversa. & & & \\
\hline $\begin{array}{l}\text { 16. Um espelho plano conjuga, para um objeto real, uma imagem simétrica ao } \\
\text { objeto. }\end{array}$ & & & \\
\hline $\begin{array}{l}\text { 17. Se o objeto for real e estiver na frente de um espelho plano, a imagem } \\
\text { conjugada será virtual (conjugada no prolongamento dos raios de luz). }\end{array}$ & & & \\
\hline $\begin{array}{l}\text { 18. Utilizando apenas espelhos planos é impossível conjugar mais que uma } \\
\text { imagem para cada objeto. }\end{array}$ & & & \\
\hline $\begin{array}{l}\text { 19. O número de imagens }(N) \text { devido à associação de espelhos planos pode ser } \\
\text { calculado pela expressão: } N=360 \% / \theta-1\end{array}$ & & & \\
\hline $\begin{array}{l}\text { 20. Considere dois espelhos planos retangulares, com a lateral de um espelho } \\
\text { encostada na lateral do outro, e com um objeto dentro do triângulo demarcado } \\
\text { pelos dois. Se for aumentado o ângulo entre os dois espelhos o número de imagens } \\
\text { do objeto também aumenta. }\end{array}$ & & & \\
\hline 21. A luz branca ao passar por um prisma se decompõe em diversas cores. & & & \\
\hline $\begin{array}{l}\text { 22. É possível decompor a luz branca com um prisma devido às diferenças entre } \\
\text { as frequências das ondas que a compõem. }\end{array}$ & & & \\
\hline 23. Ao sobrepormos luzes de cores diferentes, obteremos luz branca. & & & \\
\hline $\begin{array}{l}\text { 24. Podemos afirmar que a refração ocorre quando uma onda passa de um meio } \\
\text { a outro, em que a velocidade de propagação da onda é diferente em cada um dos } \\
\text { meios. }\end{array}$ & & & \\
\hline $\begin{array}{l}\text { 25. O índice de refração pode ser calculado pela seguinte expressão matemática } \\
\mathrm{n}_{21}=\mathrm{V}_{1} / \mathrm{V}_{2} \text {, onde } \mathrm{V}_{1} \text { é a velocidade da onda no meio } 1 \text { e } \mathrm{V}_{2} \text { é a velocidade da onda } \\
\text { no meio } 2 \text {. }\end{array}$ & & & \\
\hline $\begin{array}{l}\text { 26. O índice de refração pode ser calculado pela expressão matemática: } \\
\mathrm{n}_{21}=\operatorname{sen} \theta_{1} / \operatorname{sen} \theta_{2} \text {, onde } \theta_{1} \text { é o ângulo incidente e } \theta_{1} \text { é o ângulo refratado. }\end{array}$ & & & \\
\hline
\end{tabular}




27. Podemos afirmar que, se uma onda passa de um meio menos refringente
(menor índice de refração) para um meio mais refringente (maior índice de
refração), o raio se aproxima do normal.

28. Se a luz passar de um meio mais refringente para um menos refringente (por exemplo, do vidro para o ar), o raio de luz tende a se aproximar da normal à superfície, se o raio incidente não incidir a 900 no plano.

29. Ao passar de um meio material para o vidro, um raio luminoso sempre terá um ângulo de refração menor que o de incidência.

30. O índice de refração absoluto é dado pela relação: $n=c / v$, onde c é a velocidade da luz no vácuo e $v$ a velocidade da luz em um dos meios.

31. Para uma câmera escura funcionar corretamente (exibir uma projeção de imagem em seu interior), é necessário que haja uma lente convergente no orifício de entrada da luz.

32. Na câmera escura com lente, a lente tem a função de aumentar as dimensões do objeto e de possibilitar o registro da imagem impressa.

33. Na câmera escura com lente o tamanho da imagem depende apenas das características da lente.

34. Na máquina fotográfica analógica encontramos um conjunto de lentes.

35. O filme (material fotossensível) registra uma imagem conjugada.

36. As lentes são instrumentos que desviam os raios de luz.

37. Chamamos de transparentes os corpos que podem ser atravessados pela luz visível sem alterá-la.

38. As lentes são instrumentos ópticos que alteram a frequência das ondas luminosas.

39. As lentes convergentes possuem uma curvatura para fora.

40. Lentes com superfícies refratoras côncavas sempre transformam raios incidentes paralelos em raios emergentes convergentes. 


\begin{tabular}{|c|c|c|c|}
\hline & C & NS & D \\
\hline 41. As lentes convergentes produzem imagens sempre ampliadas. & & & \\
\hline 42. As lentes convergentes possuem sua curvatura refletora para dentro. & & & \\
\hline $\begin{array}{l}\text { 43. Se passarmos raios luminosos paralelos por uma lente divergente eles se } \\
\text { unirão em algum ponto após a lente. }\end{array}$ & & & \\
\hline 44. As lentes convergentes formam imagens ampliadas ou reduzidas. & & & \\
\hline 45. Uma das aplicações da reflexão interna total é a fibra óptica. & & & \\
\hline $\begin{array}{l}\text { 46. Em relação a um espelho convergente, há um ponto específico do espaço } \\
\text { onde todos os raios de luz provenientes dele serão refletidos pelo espelho no } \\
\text { próprio ponto. }\end{array}$ & & & \\
\hline 47. Espelhos esféricos são incapazes de formar imagens. & & & \\
\hline $\begin{array}{l}\text { 48. Um espelho esférico conjuga para um objeto real, uma imagem do mesmo } \\
\text { tamanho. }\end{array}$ & & & \\
\hline $\begin{array}{l}\text { 49. Todo raio que incide em um espelho esférico é refletido numa direção que } \\
\text { passa pelo foco principal do espelho. }\end{array}$ & & & \\
\hline $\begin{array}{l}\text { 50. Todo raio que incide numa direção que passa pelo foco de um espelho } \\
\text { esférico, é refletido paralelamente ao eixo principal. }\end{array}$ & & & \\
\hline $\begin{array}{l}\text { 51. No espelho convergente, o objeto situado antes do centro de curvatura } \\
\text { produz uma imagem real, invertida e menor do que o tamanho real do objeto. }\end{array}$ & & & \\
\hline $\begin{array}{l}\text { 52. No espelho divergente, a imagem produzida será sempre virtual, direita e } \\
\text { maior do que o tamanho real do objeto. }\end{array}$ & & & \\
\hline 53. Uma imagem virtual é conjugada na frente do espelho plano. & & & \\
\hline $\begin{array}{l}\text { 54. Uma imagem real poderá ser projetada sobre um anteparo (uma tela) } \\
\text { colocado na posição em que ela se forma. }\end{array}$ & & & \\
\hline $\begin{array}{l}\text { 55. O ponto onde se conjuga a imagem de um objeto refletido por um espelho } \\
\text { esférico é o ponto onde se encontraram os raios de luz provenientes desse objeto. }\end{array}$ & & & \\
\hline $\begin{array}{l}\text { 56. A distância focal do espelho côncavo e convexo pode ser calculada por: } f= \\
R / 2 \text {, onde } f \text { é o foco e } R \text { é o raio de curvatura. }\end{array}$ & & & \\
\hline
\end{tabular}




\begin{tabular}{|l|l|l|l|}
\hline & C & NS & D \\
\hline 57. Para a lente convergente, o foco da imagem é virtual. & & & \\
\hline 58. Para a lente divergente, o foco da imagem é virtual. & & \\
\hline 59. Uma lente divergente pode produzir imagem real. & & \\
\hline 60. Na lente divergente há somente a conjugação de imagens inversas. & & \\
\hline 61. Na lente convergente, a formação da imagem depende da posição do objeto. & & & \\
\hline 62. Na miopia, a imagem se forma antes da retina. & & \\
\hline 63. Para corrigir a miopia deve-se utilizar uma lente convergente. & & \\
\hline 64. Na hipermetropia, a imagem se forma antes da retina. & & & \\
\hline 65. Para corrigir a hipermetropia deve-se utilizar uma lente divergente. & & & \\
\hline
\end{tabular}

\section{APÊNDICE 2: CONFECÇÃO DAS ATIVIDADES EXPERIMENTAIS}

\section{ATIVIDADE 1: SIMULAÇÃO SOBRE O EFEITO DOPPLER}

A simulação sobre o efeito Doppler está disponível em: http://www.walterfendt.de/ph14br/dopplereff_br.htm. Acesso: 17 de outubro de 2010.

ATIVIDADE 2: LUZ.

Atividade extraída de Arribas (1996).

Materiais:

- 3 caixas de papelão (do tamanho de caixas de sapato), 3 pedaços grandes de fio de luz, 3 tomadas, 3 suportes para lâmpadas, 3 lâmpadas de 100 W, 3 chapas de vidro de $6 \mathrm{~cm} \times 6 \mathrm{~cm}$, tinta para vidro (azul, vermelho, verde), fita adesiva, alicate e tesoura.

Como fazer:

1) Pintar cada vidro com uma das diferentes cores. Para pintar, aconselha-se depositar um pouco de tinta na parte superior do vidro, deixar escorrer a tinta até que todo o vidro esteja pintado e deixar secar bem. 
2) Recortar um quadrado de $6 \mathrm{~cm} \times 6 \mathrm{~cm}$ na lateral menor da caixa de papelão. Nesta abertura, colocar o vidro colorido, colando-o com fita adesiva.

3) Desencapar as extremidades do fio de luz, com o auxílio do alicate. Retirar os parafusos da tomada, encaixar a extremidade desencapada do fio em seu interior e fechá-la. Conectar a outra extremidade desencapada do fio no suporte para lâmpada.

4) Recortar uma pequena abertura na outra lateral menor da caixa de papelão, de frente ao vidro colorido e no tamanho adequado para colocar a lâmpada. Posicionar a lâmpada nesta abertura e fixá-la com fita adesiva.

5) Fechar a tampa da caixa e ligar a lâmpada.

A construção das outras duas caixas é análoga a esta.

6) Observar a sobreposição de cores e como se formam as cores secundárias e terciárias a partir da mistura das cores primárias.

A atividade pronta deverá ficar conforme a Figura 3.

Figura 3- luz.

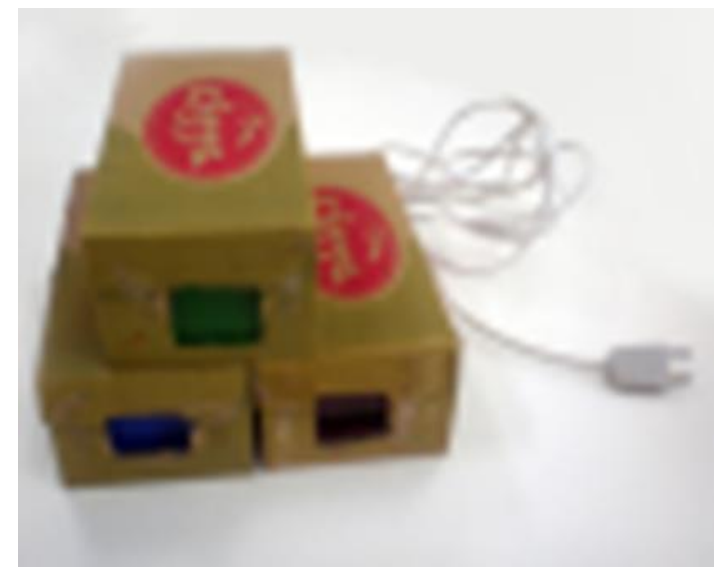

\section{Atividade 3: Persistência retiniana.}

Atividade extraída de Arribas (1996).

Materiais:

- folhas de papel, papelão, régua, barbante, cola e fita adesiva.

Como fazer:

1) Recortar quadrados de $6 \mathrm{~cm} \times 6 \mathrm{~cm}$ de papelão.

2) Depositar cola em um dos papelões, colocar o barbante sobre a cola e finalizar com mais um papelão. Assim, tem-se colados, na ordem, papelão barbante - papelão.

3) Encapar os papelões já colados com uma folha de papel.

4) Em um dos lados desenhar um pássaro e no outro, uma gaiola. 
A atividade pronta deverá ficar conforme a Figura 4.

Figura 4- Persistência retiniana.

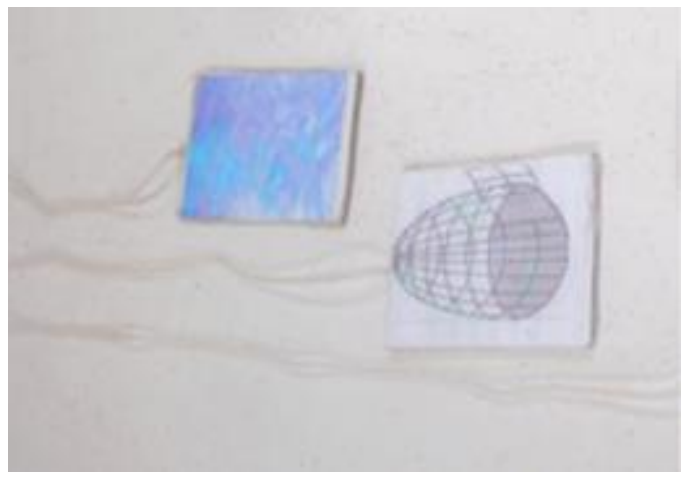

Uma alternativa é substituir o pedaço de barbante por um palito de churrasco, mantendo-se a mesma construção. Neste caso, a atividade experimental pronta ficará conforme a Figura 5.

Figura 5- Persistência retiniana.

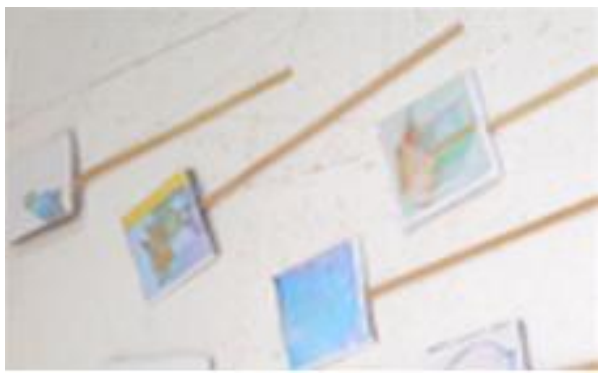

No exemplo apresentado, tem-se a ilusão de que o pássaro está dentro da gaiola, ao girar rápido o suficiente a estrutura de papelão. No entanto, outras gravuras também podem ser utilizadas, desde que, ao girar rapidamente o papelão, ocorra a junção das figuras desenhadas em cada um dos lados.

\section{ATIVIDADE 4: DISCO DE NEWTON: O MUNDO GIRANDO.}

Atividade extraída de Gaspar (2003).

Materiais:

- 4 pedaços de madeira: um com $30 \mathrm{~cm}$ de comprimento, um com $15 \mathrm{~cm}$ de comprimento, um com $10 \mathrm{~cm}$ de comprimento e outro com $5 \mathrm{~cm}$ de comprimento; 2 pregos: um grande e outro pequeno; martelo; disco de papelão com $20 \mathrm{~cm}$ de diâmetro; folhas de papel; tinta guache nas cores vermelho, azul e amarelo; alfinete; fita adesiva e cola.

Como fazer:

1) Em uma das extremidades da madeira de $30 \mathrm{~cm}$, pregar as madeiras de 15 e $10 \mathrm{~cm}$ pelo centro, juntas, utilizando o prego menor.

2) Na outra extremidade da madeira de $30 \mathrm{~cm}$, pregar a madeira de $5 \mathrm{~cm}$ utilizando o prego maior, pelo seu centro, de modo que a ponta do prego fique para fora da madeira. 
A estrutura construída deverá ficar de pé, conforme a Figura 6.

3) Em uma folha de papel, traçar um círculo com $20 \mathrm{~cm}$ de diâmetro. Dividi-lo em 12 partes, pintando cada parte, na sequência, com as cores: vermelho, azul e amarelo. Outra opção é imprimir o disco de Newton (sugestão de sites: www.equipamentoscientificos.blogspot.com, www.fisica.ufpb.br).

4) Colar o disco de Newton no disco de papelão. Perfurar o centro do conjunto com um alfinete.

5) Prender o alfinete ao prego, utilizando fita adesiva.

6) Encaixar o disco no alfinete. É importante que o disco não fique solto nem apertado, para que possa ser girado com rapidez.

7) Observa-se o que ocorre com as cores ao girar o disco.

A atividade pronta deverá ficar conforme a Figura 6.

Figura 6- Disco de Newton.

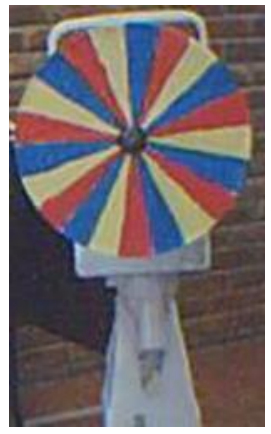

\section{ATIVIDADE 5: FENÔMENO ESTROBOSCÓPICO.}

Atividade extraída de Gaspar (2003).

Materiais:

- 4 pedaços de madeira: um com $30 \mathrm{~cm}$ de comprimento, um com $15 \mathrm{~cm}$ de comprimento, um com $10 \mathrm{~cm}$ de comprimento e outro com $5 \mathrm{~cm}$ de comprimento; 2 pregos: um grande e outro pequeno (ou a estrutura de madeira construída na atividade 4); martelo; disco de papelão com $20 \mathrm{~cm}$ de diâmetro; folha de papel; tinta guache (preta e branca).

Como fazer:

1) Em uma das extremidades da madeira de $30 \mathrm{~cm}$, pregar as madeiras de 15 e $10 \mathrm{~cm}$ também pela extremidade, juntas, utilizando o prego menor.

2) Na outra extremidade da madeira de $30 \mathrm{~cm}$, pregar a madeira de $5 \mathrm{~cm}$ utilizando o prego maior, de modo que a ponta do prego fique para fora da madeira.

3) A estrutura construída deverá ficar de pé (Figura 6). A estrutura construída na atividade 4 é a mesma utilizada nesta atividade. 
4) Desenhar um círculo de $20 \mathrm{~cm}$ de diâmetro e dividi-lo em 8 partes iguais, pintando-as alternadamente de preto e branco. Outra opção é imprimir o círculo já pintado.

5) Colar o círculo no disco de papelão. Perfurar o centro do conjunto com um alfinete.

6) Prender o alfinete ao prego, utilizando fita adesiva.

7) Encaixar o disco no alfinete. É importante que o disco não fique solto nem apertado, para que possa ser girado com rapidez.

8) Observa-se o que ocorre ao girar o disco.

O disco deverá ficar conforme a Figura 7.

Figura 7- Fenômeno estroboscópico.

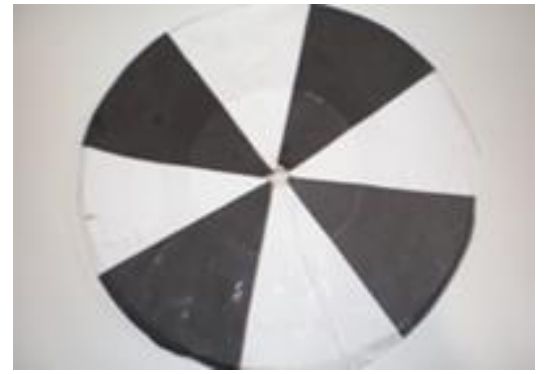

\section{ATIVIDADE 6: LEVITAÇÃO VIRTUAL.}

Atividade extraída de Valadares (2000).

Materiais:

- 4 pedaços de madeira de $48 \mathrm{~cm} \times 2,5 \mathrm{~cm} \times 2,5 \mathrm{~cm}, 8$ pedaços de madeira de $43 \mathrm{~cm} \times 2,5 \mathrm{~cm} \times 2,5 \mathrm{~cm}, 1$ espelho plano de $61 \mathrm{~cm} \times 48 \mathrm{~cm}$, cola para madeira, pregos pequenos e finos e martelo.

Como fazer:

1) Colocar as 4 madeiras menores na forma de um quadrado, colando seus vértices. Quando a cola estiver seca, pregar todos os vértices. Repetir o processo para as 4 madeiras menores restantes.

2) Unir a esta estrutura as 4 madeiras maiores, de modo a formar um paralelepípedo, pelo mesmo processo.

3) O espelho plano deve ser encaixado na diagonal da estrutura.

4) É aconselhável, para demonstração, colocar o experimento em uma superfície à altura dos olhos do observador, para que a ilusão de levitação seja mais convincente.

A atividade pronta deve ficar conforme a Figura 8. 


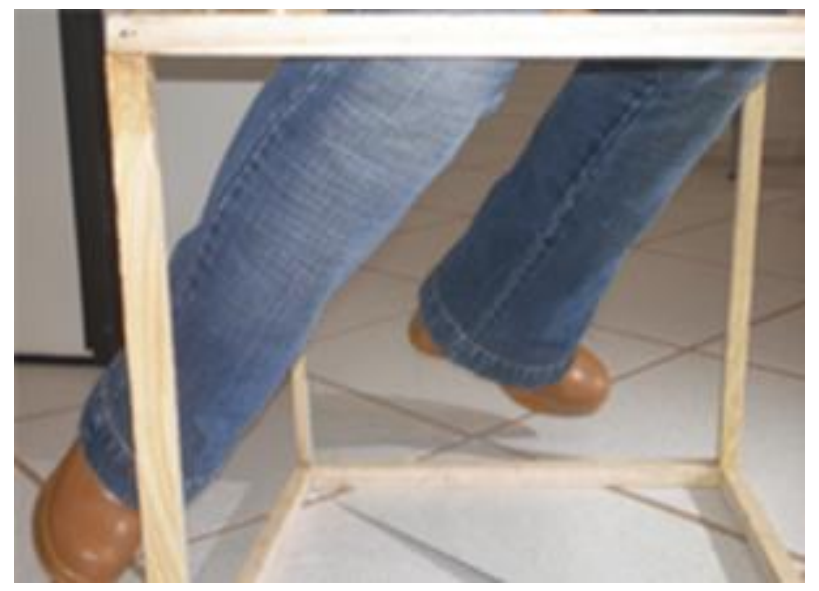

ATIVIDADE 7: PROPRIEDADES DOS ESPELHOS PLANOS.

Atividade extraída de Ribas (1996).

Materiais:

- 2 espelhos planos de $8 \mathrm{~cm} \times 10 \mathrm{~cm}$, papel milimetrado de $12 \mathrm{~cm} \times 12 \mathrm{~cm}$, papelão de $12 \mathrm{~cm} \times 12 \mathrm{~cm}$, transferidor, alfinete, lápis, fita adesiva, tesoura, cola e um pequeno objeto (cerca de $5 \mathrm{~cm}$ ).

\section{Como fazer:}

1) Traçar duas retas no papel milimetrado, uma em cada diagonal principal do quadrado de papel, cruzando o seu centro.

2) Colar o papel milimetrado sobre o papelão.

3) Colar os espelhos com fita adesiva, unindo-se uma aresta à outra, de modo que eles possam se mover livremente, mas que fiquem firmes.

4) Colocar este conjunto de espelhos sobre uma das retas feitas sobre o papel milimetrado. O centro do espelho deve ficar exatamente sobre o centro do papel milimetrado. Os ângulos devem ser marcados no papel milimetrado, com o auxílio do transferidor.

5) O objeto é colocado em frente aos espelhos e o número de imagens formadas pode ser associado ao ângulo entre os espelhos.

A atividade pronta deverá ficar conforme a Figura 9.

Figura 9- Propriedades dos espelhos planos.

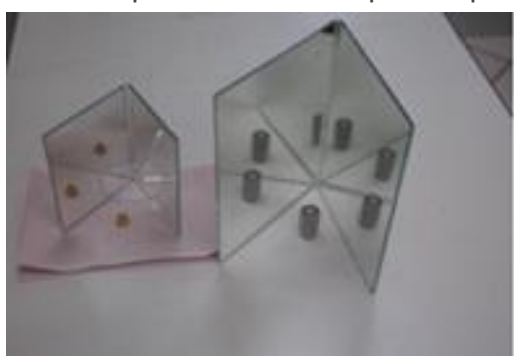


ATIVIDADE 8: CALEIDOSCÓPIO.

Atividade extraída de Berlitz (1996).

Materiais:

- 3 espelhos planos de $13 \mathrm{~cm} \times 4 \mathrm{~cm}$, papel celofane transparente, papel vegetal, folhas de papel, papel picado colorido, barbante, fita adesiva e cola.

Como fazer:

1) Unir os vértices dos 3 espelhos, com a parte refletora voltada para dentro.

2) Amarrar firmemente estas estruturas com barbante e colar uma folha de papel ao seu redor, mantendo as extremidades abertas. Deixar secar bem.

3) Em uma das aberturas menores, colar o papel celofane transparente, bem esticado. Depositar um pouco de papel picado sobre o papel celofane, do lado de fora da estrutura.

4) Colar papel vegetal sobre o papel celofane, mantendo o papel picado entre os dois. É importante colar o papel vegetal apenas nas bordas, para que o papel picado fique livre para se movimentar. Assim, em ordem, tem-se: papel celofane - papel picado - papel vegetal.

5) Observar como os pedaços de papel picado são refletidos no interior da estrutura.

A atividade pronta deverá ficar conforme a Figura 10.

Figura 10- Caleidoscópio.

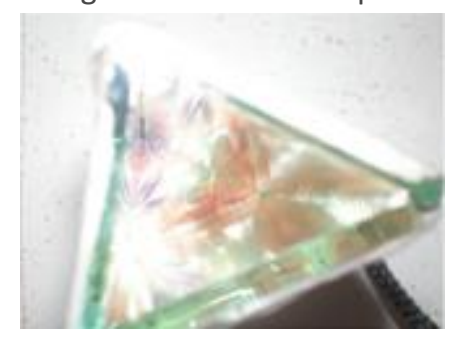

\section{ATIVIDADE 9: VIDRO INVISÍVEL.}

Atividade extraída de Valadares (2000).

Materiais:

- 2 copos lisos transparentes; 200 ml de glicerina (à venda em farmácias); duas garrafas de pimenta ou similar, com tampa de rosca, bem limpa e seca; água.

Como fazer:

1) Encher, com água, um dos copos e uma das garrafas (fechar bem a tampa). 
2) Encher, com glicerina, o outro copo e a outra garrafa (fechar bem a tampa).

3) Comparar o que ocorre ao se mergulhar a garrafa no copo de mesmo conteúdo e com conteúdo diferente.

A atividade pronta deverá ficar conforme a Figura 11.

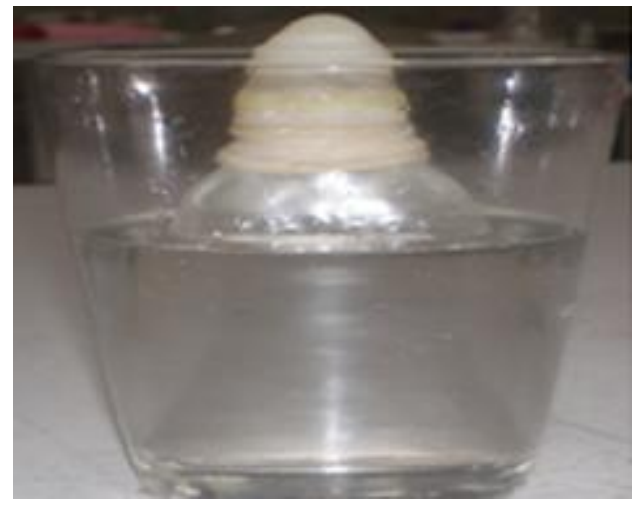

Uma alternativa é utilizar duas ampulhetas abertas e vazias, idênticas, e um copo com glicerina. Antes do início da aula, mergulhar uma ampulheta no copo. Na presença dos alunos, quebrar a outra ampulheta e depositar todos os pedaços no copo. Ao retirar a ampulheta inteira de dentro do copo, parecerá que a ampulheta quebrada magicamente foi reconstruída.

\section{ATIVIDADE 10: PRISMA RETANGULAR.}

Atividade extraída de Berlitz (1996).

Materiais:

- 8 placas de vidro de $1,5 \mathrm{~cm} \times 10 \mathrm{~cm}$, placa de isopor de $12 \mathrm{~cm} \times 12 \mathrm{~cm}$, papel milimetrado de $12 \mathrm{~cm} \times 12 \mathrm{~cm}$, alfinetes e fita adesiva.

Como fazer:

1) Desenhar uma circunferência de $12 \mathrm{~cm}$ de diâmetro sobre o papel milimetrado.

2) Traçar duas retas ortogonais que passem pelo centro da circunferência.

3) Colar o papel milimetrado sobre a placa de isopor.

4) Prender as 8 placas de vidro uma a outra pelas extremidades, com fita adesiva. Colocar o conjunto sobre uma das retas traçadas.

5) Espetar um alfinete no centro da circunferência. Espetar um segundo alfinete no quarto quadrante, à 40ㅇ da reta vertical, conforme Figura 12. 
6) Posicionar-se de tal modo que os dois alfinetes estejam alinhados. Desta posição, espetar o terceiro alfinete atrás das placas de vidro, de modo que, olhando através dos vidros, os três alfinetes estejam aparentemente alinhados.

7) Retirar uma das placas de vidro e espetar (seguindo o procedimento anterior) outro alfinete.

8) Repetir o processo, observando o que ocorre à medida que se diminui a quantidade de placas de vidro.

A atividade pronta deverá ficar conforme Figura 12.

Figura 12- Prisma retangular

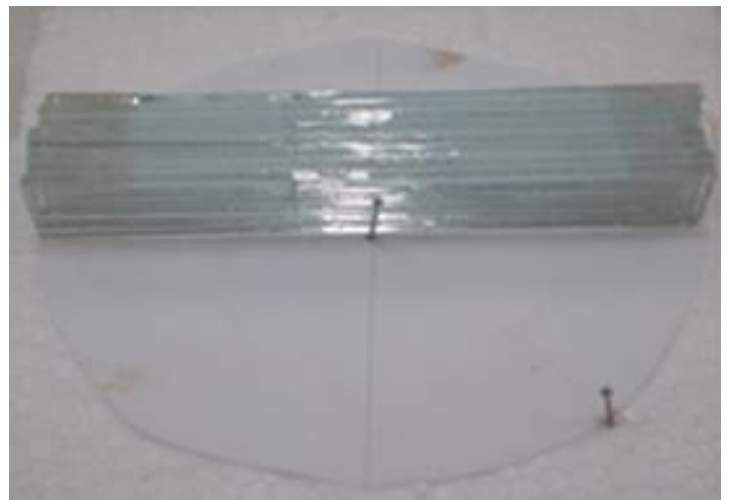

\section{ATIVIDADE 11: MANGUEIRAS DE LUZ.}

Atividade extraída de Gaspar (2003)

Materiais:

- lata de alumínio com tampa, pedaço grande de fio de luz, tomada, suporte para lâmpada, lâmpada de $100 \mathrm{~W}$, canudinho, alicate, prego, martelo, água e leite.

Como fazer:

1) Desencapar as extremidades do fio de luz, com o auxílio do alicate. Retirar os parafusos da tomada, encaixar a extremidade desencapada do fio em seu interior e fechá-la. Conectar a outra extremidade desencapada do fio no suporte para lâmpada.

2) Na tampa da lata, recortar uma pequena abertura, no tamanho adequado para colocar a lâmpada. Colocar a lâmpada nesta abertura e fixá-la com fita adesiva.

3) Fazer um pequeno orifício, com o auxílio do prego, a $2 \mathrm{~cm}$ da base inferior da lata. Inserir um pedaço pequeno de canudinho (aproximadamente 4 $\mathrm{cm})$, de tal modo que fique com a metade para dentro e a outra metade para fora da lata.

4) Colocar água até a metade da lata (convém acrescentar um pouco de 
fechado. Fechar a tampa e ligar a lâmpada. O bulbo da lâmpada não deve encostar na água.

5) Observar o que ocorre com a luz quando a água escorre pelo orifício. A atividade pronta deve ficar conforme a Figura 13.

Figura 13- Mangueiras de luz.

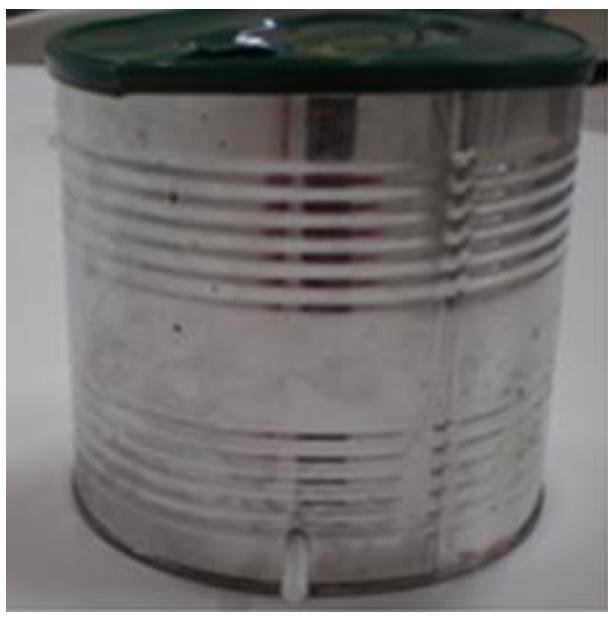

Atividade 12: Teatro mágico, Fantasma de Pepper ou Casa da Monga.

Atividade extraída de Medeiros (2005).

Materiais:

- caixa grande de papelão (aproximadamente $30 \mathrm{~cm} \times 30 \mathrm{~cm} \times 40 \mathrm{~cm}$ ) sem tampa, placa de vidro de $28 \mathrm{~cm} \times 38 \mathrm{~cm}$, cartolina preta fosca, placa de papelão (30 $\mathrm{cm} \times 30 \mathrm{~cm}$ ) para fazer a tampa da caixa, dois suportes para lâmpada, duas lâmpadas de $100 \mathrm{~W}$, potenciômetro, tomada, 3 pedaços de fio de luz: um de 3 metros, e dois de $50 \mathrm{~cm}$ (tamanhos aproximados), chave de fenda, tesoura, alicate, cola e dois objetos pequenos.

Como fazer:

1) Colar os encaixes da caixa de papelão, para que a caixa não desmonte, e, no interior da caixa, colar a cartolina preta. Recortar, em uma das laterais maiores da caixa, uma abertura de aproximadamente $20 \mathrm{~cm} \times 20 \mathrm{~cm}$.

2) Fixar o vidro dentro da caixa, na diagonal, sem deixar folga, formando duas regiões triangulares.

3) Desencapar as extremidades de todos os fios de luz, com o auxílio do alicate.

4) Retirar os parafusos da tomada, encaixar a extremidade do fio maior em seu interior e fechá-la.

5) Conectar a outra extremidade do fio maior no potenciômetro. Conectar, ainda no potenciômetro, a extremidade de um dos fios menores.

6) Conectar a outra extremidade deste fio menor ao suporte para lâmpada. 
7) Ligar os dois suportes para lâmpada utilizando o outro fio menor.

8) Fazer dois orifícios na tampa da caixa de papelão, de modo que cada um corresponda ao centro de cada região triangular da caixa. Cada lâmpada deve ficar firmemente encaixada em um dos orifícios.

9) Logo abaixo de cada lâmpada, no interior da caixa, coloca-se um dos objetos. Controlando a luminosidade pode-se modificar o objeto que é visto pela abertura lateral da caixa.

A atividade pronta deverá ficar conforme a Figura 14.

Figura 14- Teatro mágico, Fantasma de Pepper ou Casa da Monga.

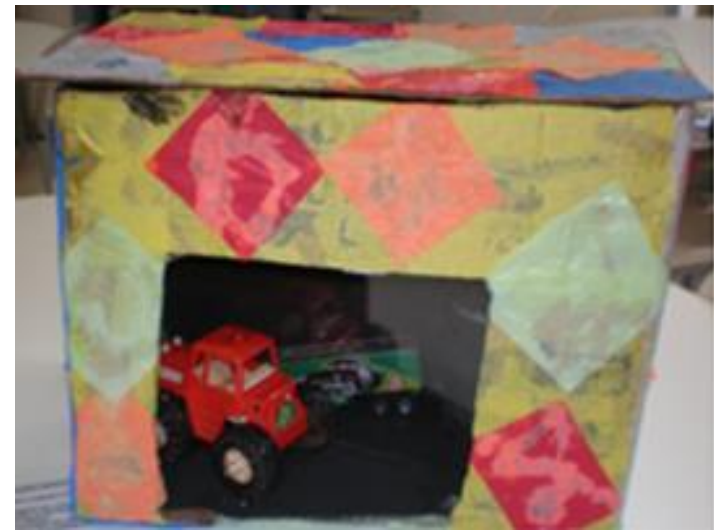

\section{ATIVIDADE 13: CÂMARA ESCURA COM LENTE:}

Atividade extraída de Berlitz (1996) e Gaspar (2003).

Materiais:

- caixa de papelão (do tamanho de uma caixa de sapato), lâmpada incandescente transparente e queimada, rolha, papel vegetal, barbante, cartolina, alfinete, arame $(40 \mathrm{~cm})$, alicate, tesoura e cola.

Como fazer:

1) Retirar o conteúdo do interior da lâmpada incandescente, enchê-la com água e tampá-la com a rolha.

2) Molhar a lâmpada, por fora, e encostá-la no centro de uma das laterais menores da caixa. Neste local, furar a caixa com o auxílio do alfinete. No centro da mesma lateral menor da caixa, fazer dois furos na altura da rolha da lâmpada e prendê-la com o auxílio do barbante.

3) Recortar na cartolina um retângulo do mesmo tamanho da caixa de papelão. Encaixá-lo, em pé, dentro da caixa, conforme mostrado na Figura 15.

4) No centro da cartolina, recortar um pequeno retângulo. Colar o papel vegetal neste espaço. Colar no centro da superfície inferior do retângulo de cartolina um arame, que deve ultrapassar o tamanho da caixa. 
5) No lado de fora da caixa, dobrar o arame fazendo uma espécie de "puxador", que deve ficar do lado oposto a lente, conforme Figura 15.

6) Ao mover o puxador, o papel vegetal será movimentado, imitando a função dos músculos ciliares no olho humano. Na atividade experimental não há possibilidade de variar o diâmetro da lâmpada, como ocorre no cristalino do olho humano, então é possível focalizar a imagem movendo-se o puxador.

Figura 15- Câmara escura com lente.

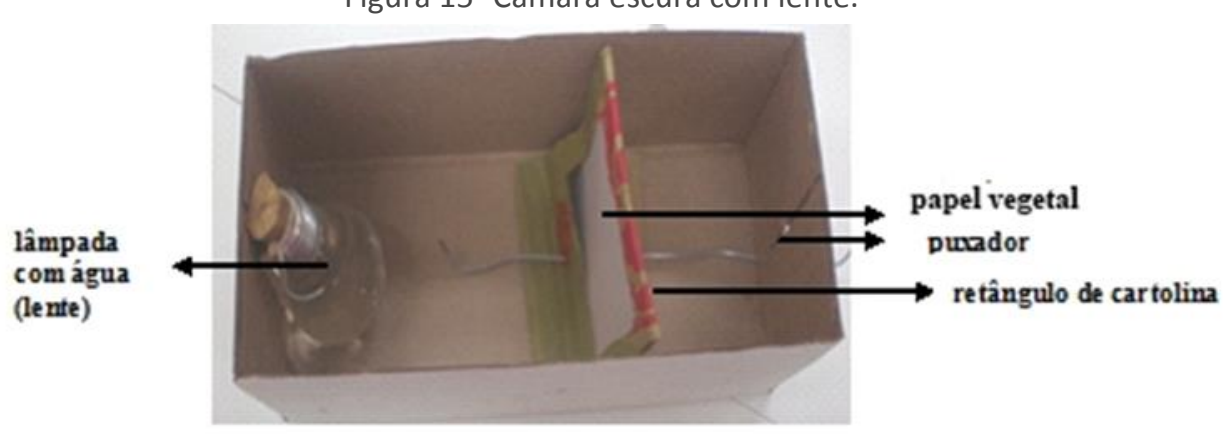

Recebido: 07 de out. de 2014

Aprovado: 22 de ago. de 2015

DOI: $10.3895 /$ rbect.v9n1.2109

Como citar:

PARISOTO, M. F.; HILGER, T. R. Investigação da aprendizagem de conceitos de óptica utilizando ilusões para turmas de pré-vestibular. Revista Brasileira de Ensino de Ciência e Tecnologia, v. 9, n. 1, p. 62-98, jan./abr. 2016. Disponível em: <https://periodicos.utfpr.edu.br/rbect/article/view/2109>. Acesso em: xxx. Correspondência:

Mara Fernanda Parisoto

Rua Pioneiro, 2153, 85950-000, Palotina, Paraná, Brasil

Thais Rafaela Hilger

Av. Gal. Carneiro, 460, 5a andar, Centro, Cep: 80060-15, Curitiba, Paraná, Brasil

Direito autoral: Este artigo está licenciado sob os termos da Licença Creative Commons-Atribuição 4.0

Internacional. 